\title{
Metode Boost-K-means untuk Clustering Puskesmas berdasarkan Persentase Bayi yang Diimunisasi
}

\author{
Boost-K-means Method for Clustering Puskesmas \\ based on Percentage of Immunized Infant
}

\author{
Ahmad Irfan Abdullah*1, Edi Winarko ${ }^{2}$, Aina Musdholifah ${ }^{3}$ \\ ${ }^{1}$ Program Studi Desain Grafis, Polimedia Kreatif, Makassar \\ 2,3 Jurusan Ilmu Komputer dan Elektronika, FMIPA UGM, Yogyakarta \\ e-mail:*1irfan@polimedia.ac.id , 2ewinarko@ugm.ac.id, 3aina_m@ugm.ac.id
}

\begin{abstract}
ABSTRAK
DOI;

10.30595/jrst.v4i2.7546

Histori Artikel:

Diajukan:

$08 / 06 / 2020$

Direvisi:

$26 / 09 / 2020$

Diterima:

$30 / 09 / 2020$

Dinas Kesehatan Kabupaten/Kota adalah satuan kerja pemerintahan daerah kabupaten/kota yang bertanggung jawab menyelenggarakan urusan pemerintahan dalam bidang kesehatan di kabupaten/kota. Pelayanan kesehatan adalah upaya yang diberikan oleh Puskesmas kepada masyarakat, mencakup perencanaan, pelaksanaan, evaluasi, pencatatan, pelaporan, dan dituangkan dalam suatu sistem. Pada penelitian ini, akan digunakan data persentase bayi yang diimunisasi yang merupakan salah satu layanan dari Puskesmas. Pelayanan imunisasi ini merupakan pelayanan imunisasi dasar meliputi BCG, DPT/HB1-3, polio 1-4 dan campak. Data persentase bayi yang diimunisasi belum memiliki pengelompokan sehingga pada penelitian ini akan diterapkan metode clustering untuk melakukan pengelompokan Puskesmas berdasarkan persentase bayi yang diimunisasi. Data persentase bayi dari masing-masing Puskesmas dijadikan data uji yang akan diterapkan pada proses multi-clustering dengan metode boostclustering. Output dari penerapan metode ini akan dibandingkan dengan output metode clustering dasar k-means, hasil clustering akan diukur menggunakan metode silhouette index. Evaluasi menggunakan metode silhouette index dilakukan pada dataset puskesmas. Analisis dilakukan dengan melihat hasil evauasi dataset yang sudah diimplementasikan kedalam algoritma cluster dasar k-means dan algoritma multiclustering boost-k-means. Berdasarkan hasil evaluasi, diperoleh nilai silhouette index 0,798102756 untuk k-means dan 0,789901932 untuk boost-kmeans, dengan ini algoritma yang diusulkan memiliki kualitas hasil clustering minimal sama atau lebih baik dari single clustering k-means dengan jumlah iterasi yang lebih sedikit.
\end{abstract}

Kata Kunci: k-means; multi-clustering; boost-clustering; boost-k-means.

\footnotetext{
ABSTRACT

District Health Office is a working unit of local government districts/cities are responsible for organizing the affairs of government in the health sector in the district/city. Health services are efforts exerted by the health center to the community, including planning, implementation, evaluation, recording, reporting, and contained in a system. In this study, used percentage of infants immunized data which is one of the services of Puskesmas. Immunization services is a basic immunization services include BCG, DPT/HB1-3, 1-4 polio and campak. Data percentage of infants who were immunized yet have a grouping so that this research will be applied clustering methods to grouping Puskesmas by the percentage of infants immunized. Data percentage of children from each Puskesmas used as test data to be applied to multi-
} 
clustering process with boost-clustering method. Output from the application of these methods will be compared with the output method basic k-means clustering, the clustering results will be measured using methods silhouette index. Silhouette index evaluation methods performed on puskesmas dataset. The output of clustering have been analyzed by looking at the results of evaluation on dataset, that has been implemented into the single cluster algorithm k-means and multi-clustering algorithm boost-k-means. Based on the evaluation results, the value of silhouette index is 0,798102756 for k-means and 0,789901932 for boost-k-means, the proposed algorithm has the quality of the clustering of at least the same or better than single k-means clustering with fewer number of iterations.

Keywords: k-means; multi-clustering; boost-clustering; boost-k-means.

\section{PENDAHULUAN}

Dinas Kesehatan Kabupaten/Kota adalah satuan kerja pemerintahan daerah kabupaten/kota yang bertanggung jawab menyelenggarakan urusan pemerintahan dalam bidang kesehatan di kabupaten/kota. Fasilitas pelayanan kesehatan adalah suatu tempat yang digunakan untuk menyelenggarakan upaya pelayanan kesehatan, baik promotif, preventif, kuratif maupun rehabilitatif yang dilakukan oleh pemerintah, pemerintah daerah dan/atau masyarakat. Pada data persentase bayi yang diimunisasi belum memiliki pengelompokan persentase layanan, sehingga pada penelitian ini akan digunakan sebagai data uji dalam penerapan metode multi-clustering, boost-clustering dengan algortima clustering dasar $k$-means.

Diharapkan dari hasil clustering diperoleh pengelompokan Puskesmas yang bisa memberikan informasi mengenai Puskesmas yang sudah memenuhi target layanan imunisasi bayi, belum memenuhi target layanan imunisasi bayi dan melebihi target layanan imunisasi bayi.

Pendekatan multi-clustering dengan metode boost-clustering (Frossyniotis, D., dkk., 2004) , merupakan metode multi-clustering dengan tujuan menghasilkan peningkatan kualitas dan ketahanan kinerja proses clustering. Metode ini diharapkan dapat meningkatkan hasil clustering dasar k-means yang akan digunakan pada penelitian ini, yang akan di ukur menggunakan silhouette index.

Metode pada clustering telah dikembangkan oleh banyak peneliti dengan menggunakan berbagai metode untuk berbagai kasus. Berikut beberapa diantaranya, (Wang, R., dkk., 2011) penelitian ini menggunakan metode $K$-means dalam melakukan pengelompokan sumber daya perpustakaan untuk meningkatkan layanan perpustakaan sesuai kebutuhan pengguna. Hasil dari masing-masing metode yang digunakan sudah dapat menyelesaikan permasalahan tetapi belum menyentuh pada tahap peningkatan hasil clustering. Pada penelitian yang akan penulis lakukan, diharapkan ada peningkatan terhadap hasil clustering $k$ means ketika dijalankan dalam proses multiclustering.

Penelitian berikutnya (Ahalya, G. \& Pandey, H.M., 2015) menekankan pada pemahaman beberapa metode clustering untuk memudahkan para pemula memahami cara kerja dari algorithma clustering. Dalam penelitian ini dibahas 5 metode clustering, yaitu algoritma $k$ means, algoritma clustering hirarki, algoritma clustering density based, algoritma selforganizing map (SOM) dan algoritma expectation maximization (EM). Pada penelitian ini algoritma clustering dasar seperti yang telah disebutkan akan dijalankan masing-masing, sedangkan pada penelitian yang akan penulis lakukan algoritma clustering dasar akan dijalankan didalam proses multi-clustering.

Penelitian berikut (Elssied, N.O.F., dkk., 2014) mengenai deteksi spam pada email, menggunakan metode support vector machine (SVM) dan k-means. Hasil yang diperoleh pada penelitian ini, yaitu dengan melakukan hybrid system menerapkan metode SVM dengan $k$ means dapat meningkatkan akurasi menjadi $98,01 \%$ dari yang tadinya $96,30 \%$ ketika hanya menggunakan metode SVM.

Penelitian selanjutnya bertema multiclustering, penelitian ini (Frossyniotis, D., dkk., 2004) menggunakan metode boosting untuk melakukan clustering. Algoritma clustering dasar dibutuhkan pada proses boost-clustering , misalnya menggunakan $k$-means. Solusi clustering akhir dihasilkan dengan menggabungkan beberapa hasil clustering melalui voting pembobotan sesuai distribusi yang telah dilakukan sebelumnya. Percobaan pada kedua dataset buatan dan dunia nyata menunjukkan 
bahwa solusi boost-clustering memberikan peningkatan kualitas terhadap hasil clustering. Penelitian berikut (Li C.A., 2009) , melakukan penelitian yang merupakan variant dari algortima boosting, proses boosting yang dilakukan, sama dengan yang dilakukan oleh penelitian (Frossyniotis, D., dkk., 2004) . Perbedaanya yaitu, penelitian ini distribusi data dilakukan menurut atribut yang telah melalui proses feature selection, atribut yang dianggap penting akan dihitung untuk menghasilkan nilai untuk update distribusi atribut, sehingga pada akhirnya terbentuk terbentuk cluster pada dataset yang telah diberi pembobotan.

Penelitian selanjutnya (Rashedi., E. \& Mirzaei., A., 2011) , memperkenalkan metode multi-clustering boosting untuk mengetahui tipe cluster yang baik digunakan pada metode boosting, hasilnya tipe cluster centroid dan average yang lebih baik untuk digunakan. Sedangkan pada penelitian berikut (Li., C \& Wu T., 2006) , telah dibuktikan bahwa clustering menggunakan metode boosting dapat menangani data yang sulit untuk dikelompokkan pada data yang heterogen dan dapat meningkatkan akurasi clustering untuk data yang terpusat.

Pada penelitian berikut akan dilakukan dengan menggunakan dua metode, penelitian (Lisangan, E.A., Musdholifah, A. \& Hartati S., 2015) menggunakan metode Fuzzy Subtractive Clustering (FSC) dan Self-Organizing Map (SOM). Menggunakan pengujian yang salah satunya adalah silhouette index, penelitian ini menunjukkan bahwa FSC-SOM dapat memperbaiki pusat cluster yang dihasilkan oleh FSC dengan SOM sehingga dapat diperoleh kualitas eksternal dan internal hasil clustering yang lebih baik.

\section{METODE PENELITIAN}

\subsection{K-means}

Dalam statistik dan mesin pembelajaran, clustering $k$-means merupakan metode analisis cluster yang mengarah pada pemartisian $\mathrm{N}$ objek pengamatan ke dalam K cluster (cluster) di mana setiap objek pengamatan dimiliki oleh sebuah cluster dengan mean (rata-rata) terdekat, mirip dengan algoritma Expectation-Maximization untuk Gaussian Mixture di mana keduanya mencoba untuk menemukan pusat dari cluster dalam data sebanyak iterasi perbaikan yang dilakukan oleh kedua algoritma.
K-means merupakan salah satu metode clustering data nonhierarki (sekatan) yang berusaha mempartisi data yang ada ke dalam bentuk dua atau lebih cluster. Metode ini mempartisi data yang ada ke dalam bentuk dua atau lebih cluster. Metode ini mempartisi data ke dalam cluster sehingga data berkarakteristik sama dimasukkan kedalam satu cluster yang sama dan data yang berkarakteristik yang berbeda dikelompokkan dalam cluster yang lain. Adapun tujuan clustering data ini adalah untuk meminimalkan fungsi objektif yang di set dalam suatu cluster dan memaksimalkan variasi antar cluster.

Clustering data dengan metode $k$-means ini secara umum dilakukan dengan algoritma seperti berikut (Prasetyo, E., 2012) :

1. Tentukan jumlah cluster.

2. Alokasikan data ke dalam cluster secara acak.

3. Hitung pusat kelompok (centroid/rata-rata) dari data yang ada di masing-masing cluster.

4. Alokasikan masing-masing data ke centroid/rata-rata terdekat

5. Kembali ke langkah 3, apabila masih ada data yang berpindah cluster, atau apabila ada perubahan nilai centroid di atas nilai ambang yang di tentukan, atau apabila perubahan nilai pada fungsi objektif yang digunakan masih di atas nilai ambang yang ditentukan.

Persamaan (1) dilakukan sebanyak $p$ dimensi sehingga $i$ mulai dari 1 sampai $p$. Pada penelitian ini peneliti akan menggunakan persamaan Euclidian untuk mengukur jarak data ke pusat cluster sehingga didapatkan jarak terpendek antara dua titik.

$$
\mathrm{D}\left(\mathrm{x}_{2}, \mathrm{x}_{1}\right)=\sqrt{\sum_{\mathrm{j}=1}^{\mathrm{p}}\left(\mathrm{x}_{2 j}-x_{1 j}\right)^{2}}
$$

Pada langkah ke 4 menggunakan persamaan (2), pengalokasian kembali data ke dalam masing-masing cluster dalam metode $k$ means didasarkan pada perbandingan jarak antara data dengan centroid setiap cluster yang ada. Data dialokasikan ulang secara tegas ke cluster yang mempunyai centroid dengan jarak terdekat dari data tersebut. Pengalokasian ini dapat dirumuskan sebagai berikut :

$$
a_{i 1}=\left\{\begin{array}{rr}
1 & \mathrm{~d}=\min \left\{\mathrm{D}\left(\mathrm{x}_{\mathrm{i}}, \mathrm{C}_{1}\right)\right\} \\
0 & \text { lainnya }
\end{array}\right.
$$


Apabila masih ditemukan data yang berpindah cluster, maka digunakan persamaan (3) :

$$
J=\sum_{i=1}^{N} \sum_{1=1}^{K} a_{i c} D\left(x_{i}, C_{1}\right)^{2}
$$

Dimana $\mathrm{N}$ adalah jumlah data, $\mathrm{K}$ adalah jumlah cluster, $\mathrm{a}_{\mathrm{il}}$ adalah nilai keanggotaan titik data $\mathrm{x}_{\mathrm{i}}$ ke pusat cluster $\mathrm{C}_{1}, \mathrm{C}_{1}$ adalah pusat cluster ke- 1 , dan $\mathrm{D}\left(\mathrm{x}_{\mathrm{i}}, \mathrm{C}_{1}\right)$ adalah jarak titik $\mathrm{x}_{\mathrm{i}}$ ke cluster $\mathrm{C}_{1}$ yang diikuti. a mempunyai nilai 0 atau 1 . Apabila suatu data merupakan anggota suatu cluster, nilai $\mathrm{a}_{\mathrm{il}}=1$.Jika tidak, nilai $\mathrm{a}_{\mathrm{il}}=0$.

Proses multi-clustering melakukan pembentukan cluster pada dataset dengan menggunakan metode cluster dasar yang dijalankan pada metode multi-clustering dalam satu proses. Sehingga dalam pembentukan cluster ada perbedaan pada komponen-komponen input dan metode yang digunakan untuk menghasilkan cluster pada setiap iterasi. Proses multi-clustering terdiri dari algoritma multi-clustering dan sebuah algoritma cluster dasar, pada penelitian ini digunakan algoritma multi-clustering boosting dan algoritma cluster dasar $k$-means.

\subsection{Boost-clustering}

Multi-clustering merupakan teknik untuk menggabungkan beberapa algoritma clustering dasar untuk menghasilkan sebuah data cluster (Ashlock, D. dan Guo, L., 2007) . Algoritma yang dapat digunakan untuk multi-clustering salah satunya dengan menggunakan boost-clustering (Frossyniotis, D. dkk., 2004) .

\subsection{Algoritma Boost-clustering}

Algoritma boost-clustering merupakan pendekatan multi-clustering yang secara iteratif mendaur ulang contoh pelatihan, menyediakan beberapa clustering dan menghasilkan partisi umum.

Diberikan data input yang beurutan seperti contoh $N$ berikut, $\left(x_{1}, \ldots, x_{N}\right),\left(x_{i} \in\right.$ $\left.R^{d}\right), \quad i=1, \ldots, N$, sebuah algoritma dasar clustering, jumlah C cluster untuk partisi data set dan jumlah maksimum iterasi T. Pada algoritma boost-clustering (Frossyniotis, D., dkk., 2004) clustering akan dilakukan dengan langkahlangkah seperti berikut :
1. Inisialisasi distribusi bobot awal $w_{i}^{1}=\frac{1}{N}$ untuk $i=1, \ldots ., N$. Tetapkan, $\epsilon_{\max }=0$ dan $i c=0$

Dimana : $N=$ Jumlah Data

$$
\begin{aligned}
& \epsilon_{\text {max }}=\text { Nilai pseudoloss awal } \\
& i c=\text { iterasi untuk stopping }
\end{aligned}
$$

criteria pseudoloss

2. Pada kondisi iterasi $t \leq T$

a. Lakukan proses clustering dengan algoritma clustering dasar, untuk mempartisi dataset sehingga didapatkan partisi dari $H^{t}$ yang merupakan hasil dari proses pembentukan cluster dasar.

Dimana : $t=$ jumlah iterasi

$$
T=\text { iterasi maksimum }
$$

b. Pada tahapan ini cluster hypothesis awal $H_{i}^{t}$ telah diperoleh, $H_{i}^{t}=$ $\left(h_{i, 1}^{t}, h_{i, 2}^{t}, h_{i, 3}^{t}, \ldots, h_{i, C}^{t}\right)$ untuk semua $i, i=1, \ldots . N$, dimana $h_{i, j}$ merupakan derajat keanggotaan dari data $i$ terhadap cluster. Simbol $h_{i, j}$ merupakan hasil perbadingan nilai jarak dari cluster dasar pada masing-masing data dan cluster. Persamaan (4) berikut digunakan untuk memperoleh nilai $h_{i, j}$ :

$$
h_{i, j}=\frac{1}{\sum_{k=1}^{C} \frac{d\left(x_{i}, \mu_{j}\right)}{d\left(x_{i}, \mu_{k}\right)}}
$$

Dimana :

$$
\begin{aligned}
& d\left(x_{i}, \mu_{j}\right) \& d\left(x_{i}, \mu_{k}\right)=\text { Nilai euclidien } \\
& \text { distance hasil proses } k \text {-means. }
\end{aligned}
$$

c. Jika iterasi sudah lebih dari satu kali $(t>$ $1)$, lakukan penggantian anggota cluster $H^{t}$ berdasarkan hasil cluster aggregate hypothesis $H_{a g}^{t-1} \cdot H_{a g}^{t-1}$ merupakan hasil pembentukan cluster hypothesis aggregate iterasi sebelumnya.

d. Proses selanjutnya hitung Pseudoloss dengan persamaan (5)

$$
=\frac{1}{2} \sum_{i=1}^{N} w_{i}^{t} C Q_{i}^{t}
$$

$$
\epsilon_{t}
$$

sebelum persamaan (5) terlebih dahulu dilakukan perhitungan untuk mendapatkan nilai kulitas clustering $C Q$ dengan persamaan (6)

Dimana :

$$
w_{i}^{t}=\text { Nilai bobot masing-masing data }
$$




$$
\begin{aligned}
& C Q_{i}^{t} \\
& =-\sum_{j=1}^{C} h_{i, j}^{t} \log \left(h_{i, j}^{t}\right)
\end{aligned}
$$

Dimana :

$C Q_{i}^{t}=$ Nilai cluster quality masingmasing data

$h_{i, j}^{t} \quad=$ Nilai cluster hypothesis awal

e. Tetapkan nilai $\beta_{t}$ dengan persamaan (7),

$$
\beta_{t}=\frac{1-\epsilon_{t}}{\epsilon_{t}}
$$

Hasil dari perhitungan ini akan digunakan pada proses update bobot.

f. Diberikan kondisi seperti berikut :

(i) Jika $\epsilon_{t}>0.5$ maka,

$$
T=t-1
$$

lakukan langkah ke 3

(iterasi boost-clustering berhenti)

(ii) Jika $\epsilon_{t}>\epsilon_{\max }$ maka

$i c=i c+1$

Jika $i c=3$ maka $T=t$

lakukan langkah ke 3

(iterasi boost-clustering

berhenti)

Jika tidak

$i c=0$

$$
\epsilon_{\max }=\epsilon_{t}
$$

ic merupakan iterasi dengan

kondisi $\epsilon_{t}>\epsilon_{\max }$

g. Proses berikutnya lakukan update distribusi bobot dari $W$ dengan mengunakan persamaan (8):

$$
w_{i}^{t+1}=\frac{w_{i}^{t} \beta_{t}^{C Q_{i}^{t}}}{Z_{t}}
$$

Pada persamaan ini, $Z_{t}$ merupakan normalisasi yang konstan yang akan selalu menghasilkan nilai $w_{i}^{t+1}=1$.

Dimana :

$w_{i}^{t+1}=$ update distribusi bobot dengan jumlah iterasi lebih dari 1 kali

h. Menggunakan persamaan (9) hitung aggregate dari cluster hypothesis awal :

$$
H_{a g}^{t}=\arg \max _{k=1, \ldots, C} \sum_{\tau=1}^{t}\left[\frac{\log \left(\beta_{\tau}\right)}{\sum_{j=1}^{t} \log \left(\beta_{j}\right)} h_{i, k}^{\tau}\right]
$$

i. Nilai iterasi, sesuai dengan kondisi $t:=$ $t+1$

\section{Dimana :}

$$
\begin{aligned}
& h_{i, k}^{\tau}=\text { Nilai cluster hypothesis } \\
& \text { awal }
\end{aligned}
$$

3. Output pada jumlah iterasi $T$ (akhir) akan menjadi cluster final $H^{f}$ yang sebenarnya merupakan nilai dari cluster aggregate hypothesis atau $H^{f}=H_{a g}^{t}$.

Dimana :

$H^{f}=$ Cluster aggregate hypothesis $H_{a g}^{t}$ pada iterasi terakhir (maksimum).

\subsection{Silhouette Index}

Pengujian adalah faktor penting untuk mengetahui validitas dari hasil penelitian yang sudah dilakukan. Hasil pengujian akan memberikan informasi jumlah cluster yang baik untuk dataset yang telah melalui proses clustering. Untuk menghitung nilai silhouette index dari sebuah data ke- $i$ ada 2 komponen yaitu $a_{i}$ dan $b_{i}, a_{i}$ adalah rata-rata jarak data ke-i terhadap semua data lainnya dalam satu cluster, sedangkan $b_{i}$ didapatkan dengan menghitung rata-rata jarak data ke-i terhadap semua data dari cluster yang lain tidak dalam satu cluster dengan data ke-i, kemudian diambil yang terkecil (Tan, Pang-Ning., dkk. 2006).

Nilai silhouette index dari data ke-i $(S(i))$ didapatkan dengan perhitungan dengan menggunakan persamaan (10).

$$
S(i)=\frac{(b(i)-a(i))}{\max (a(i), b(i))}
$$

Pada persamaan (10), $a(i)$ merupakan jarak rata-rata data ke-i terhadap data yang terdapat dalam cluster yang sama sedangkan $b(i)$ merupakan jarak rata-rata terkecil data ke-i terhadap data yang terdapat pada masing-masing cluster yang berbeda.

$$
\begin{gathered}
a(i)=\frac{\sum d(i, j)}{n_{C i}}, i, j \in C_{i} \\
b(i)=\min _{C k \neq C i}\left\{\frac{\sum d i s t(i, j)}{n_{C i}}\right\}, i \in C_{i} \text { dan } k \in C_{k}
\end{gathered}
$$

Nilai $a(i)$ diperoleh dengan menggunakan persamaan (11) dan untuk nilai $b(i)$ digunakan persamaan (12), dist $(i, j)$ merupakan jarak antara titik ke-i terhadap titik ke-j, $n_{C i}$ merupakan jumlah titik yang ada dalam cluster ke-i sedangkan $n_{C k}$ merupakan jumlah titik yang ada dalam cluster ke-k. 
Nilai rata-rata silhouette index dihitung menggunakan persamaan (13), dengan menjumlahkan keseluruhan nilai silhouette index untuk setiap data. $S(i)$ selanjutnya dibagi dengan jumlah data keseluruhan (n).

$$
S=\frac{1}{\mathrm{n}} \sum_{i=1}^{n} S(i)
$$

Nilai $a_{i}$ akan menjadi tolak ukur tingkat kemiripan sebuah data dengan cluster yang diikutinya, nilai yang semakin kecil menandakan tingkat ketepatan data tersebut berada pada sebuah cluster. Nilai $b_{i}$ yang besar menandakan tingkat keburukan data terhadap cluster lain (Prasetyo, E., 2012). Silhouette index memiliki rentang nilai $[-1,+1]$. Nilai silhouette index yang mendekati 1 menandakan tingkat ketepatan data tersebut berada pada sebuah cluster.

\section{HASIL DAN PEMBAHASAN}

Pengujian hasil clustering dengan metode silhouette index dilakukan dengan rentang jumlah cluster 2 (dua) sampai 10 (sepuluh) pada dataset puskesmas. Pada dataset puskesmas akan diimplementasikan kedalam model aplikasi dan dijalankan masing-masing sebanyak 3 (tiga) kali, kemudian akan diamati hasil pengujian terbaik dari proses yang sudah dilakukan. Pada Tabel 1 akan ditampilkan daftar hasil pengujian terbaik, dari silhouette index untuk kedua metode yang digunakan pada dataset puskesmas sebagai data uji yang telah di evaluasi.

Tabel 1. Daftar hasil evaluasi silhouette index terbaik

\begin{tabular}{c|c|c|c|c}
\hline $\begin{array}{c}\text { Nama } \\
\text { Dataset }\end{array}$ & $\begin{array}{c}\text { Jumlah } \\
\text { Cluster } \\
\text { Class } \\
\text { Puskesmas }\end{array}$ & $\begin{array}{c}\text { Jumlah } \\
\text { Data }\end{array}$ & K-means & $\begin{array}{c}\text { Boost-K- } \\
\text { means }\end{array}$ \\
& 2 & 379 & 0,798102756 & 0,789901932 \\
& 3 & & 0,548522359 & 0,604693087 \\
& 4 & & 0,538086698 & 0,324902421 \\
& 5 & 0,431282336 & 0,411477976 \\
& 6 & 0,42423929 & 0,304520716 \\
& 7 & 0,395997746 & 0,330222033 \\
& 8 & 0,354574449 & 0,251810304 \\
& 9 & 0,329903844 & 0,183443325 \\
& 10 & 0,349047852 & 0,274783902 \\
\hline
\end{tabular}

Hasil clustering pada dataset puskesmas kemudian diuji menggunakan silhouette index, pada dataset puskesmas diperoleh hasil pengujian terbaik pada jumlah cluster 2 untuk kedua algoritma yang digunakan, dengan nilai rata-rata 0,798102756 untuk clustering dengan $k$-means dan 0,789901932 untuk clustering boost$k$-means.

Pada dataset puskesmas untuk jumlah cluster 3 nilai yang lebih besar diperoleh pada metode boost-k-means dibandingkan $k$-means. Perbandingan jarak rata-rata intracluster dengan jarak rata-rata intercluster, menggunakan alat ukur silhouette index untuk mengukur kualitas hasil clustering menunjukkan bahwa, pada dataset puskesmas hasil clustering dari metode boost-k-means dan $k$-means memiliki kualitas minimal sama.

Pada Tabel 2 ditunjukkan nilai rata-rata evaluasi silhouette index $k$-means yang dihitung berdasarkan hasil percobaan sebelumnya yang dilakukan masing-masing sebanyak 3 kali untuk setiap jumlah cluster.

Tabel 2. Rata-rata evaluasi silhouette index $k$ means

\begin{tabular}{l|c|c|ccc}
\hline $\begin{array}{l}\text { Nama } \\
\text { Dataset }\end{array}$ & $\begin{array}{l}\text { Jumlah } \\
\text { Cluster/ } \\
\text { Class }\end{array}$ & $\begin{array}{l}\text { Jumlah } \\
\text { Data }\end{array}$ & \multicolumn{3}{|c}{$\begin{array}{l}\text { Rata - rata } \\
\text { Sihouette Index }\end{array}$} \\
\cline { 4 - 6 } & & & \multicolumn{3}{|c}{ K-means } \\
\cline { 3 - 6 } & 2 & 379 & 0,798102756 & \pm & 0 \\
\hline Puskesmas & 3 & & 0,458437654 & \pm & 0,084262217 \\
& 4 & & 0,517049787 & \pm & 0,036436999 \\
& 5 & 0,420574668 & \pm & 0,009273113 \\
& 6 & & 0,423568512 & \pm & 0,001161821 \\
& 7 & & 0,357605228 & \pm & 0,033716458 \\
& 8 & 0,318945046 & \pm & 0,048430895 \\
& 9 & 0,271917243 & \pm & 0,051937356 \\
& 10 & 0,270924631 & \pm & 0,091413321 \\
\hline
\end{tabular}

Tabel 3 ditunjukkan nilai rata-rata evaluasi silhouette index boost-k-means yang dihitung berdasarkan hasil percobaan sebelumnya yang dilakukan masing-masing sebanyak 3 kali untuk setiap jumlah cluster. 
Tabel 3. Rata-rata evaluasi silhouette index boost$k$-means

\begin{tabular}{ccccc}
\hline \multirow{2}{*}{$\begin{array}{c}\text { Nama } \\
\text { Dataset }\end{array}$} & $\begin{array}{c}\text { Jumlah } \\
\text { Cluster/ } \\
\text { Class }\end{array}$ & $\begin{array}{c}\text { Jumlah } \\
\text { Data }\end{array}$ & \multicolumn{2}{c}{$\begin{array}{c}\text { Rata - rata } \\
\text { Sihouette Index }\end{array}$} \\
\cline { 3 - 5 } & & & \multicolumn{2}{c}{ Boost-K-means } \\
\hline Puskesmas & 2 & 379 & 0,224769957 & $\pm 0,584610864$ \\
& 3 & & 0,120820436 & $\pm 0,471813181$ \\
& 4 & & 0,016064497 & $\pm 0,314932836$ \\
& 5 & 0,094360467 & $\pm 0,334757734$ \\
& 6 & 0,054818794 & \pm & 0,247125716 \\
& 7 & 0,068949479 & \pm & 0,272730902 \\
& 8 & 0,034349551 & \pm & 0,223164993 \\
& 9 & 0,014251309 & \pm & 0,16880279 \\
& 10 & 0,034860031 & \pm & 0,243963218 \\
\hline
\end{tabular}

Hasil clustering dari 3 kali percobaan pada dataset puskesmas dan masing-masing jumlah cluster memiliki perbedaan dalam jumlah anggota dari masing-masing cluster sehingga hasil pengujian yang diperoleh juga berbeda-beda, seperti yang ditampilkan pada Tabel 2 dan Tabel 3. Keberagaman hasil clustering paling minimal $=$ 0 diperoleh pada metode k-means dengan jumlah cluster 2, sedangkan keberagaman hasil clustering paling minimal pada metode boost- $k$ means dengan nilai satandar deviasi = 0,014251309 pada jumlah cluster 9 .

Hasil proses clustering juga dapat dilihat dalam bentuk visualisasi grafik scatter, pada Gambar 1 akan ditampilkan visualisasi sebaran masing-masing dataset dengan hasil pengujian silhouette index terbaik.

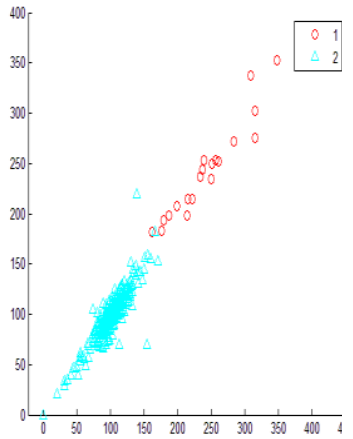

a. Puskesmas k-means

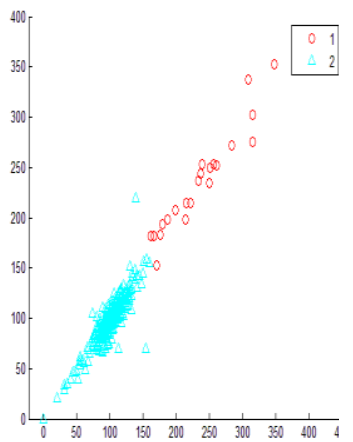
means b. Puskesmas boost- $k$ -

Gambar 1. Visualisasi sebaran dataset hasil clustering

Visualisasi yang ditunjukkan oleh Gambar 1a dan Gambar 1b merupakan sebaran dataset puskesmas dengan jumlah cluster 2. Gambar 1a merupakan sebaran dataset puskesmas hasil clustering dengan k-means dan Gambar 1b sebaran dataset puskesmas hasil clustering boost$k$-means. Pada dataset puskesmas nilai kerapatan intracluster lebih baik pada boost-k-means dibanding $k$-means sedangkan nilai kerenggangan intercluster lebih baik pada $k$-means dibanding boost-k-means.

\section{KESIMPULAN}

Setelah melakukan serangkaian penelitian mulai dari pengumpulan data, perancangan, implementasi dengan metode single dan multiclustering serta melakukan pengujian pada hasil clustering dengan dua alat ukur yang berbeda masing-masing dataset, maka dapat disimpulkan bahwa, metode multi-clustering boosting yang menjalankan metode cluster dasar $k$-means (boost-k-means) untuk dataset puskesmas memiliki kualitas hasil cluster terbaik yang sama dengan hasl clustering oleh metode single clustering k-means, yaitu pada jumlah cluster 2 (dua), dengan jumlah iterasi yang lebih sedikit pada metode multi-clustering boost-k-means.

\section{UCAPAN TERIMA KASIH}

Terima kasih kepada Dinas Kesehatan Provinsi Sulawesi Selatan yang telah bersedia membantu terkait data yang dijadikan objek pada penelitian ini.

\section{DAFTAR PUSTAKA}

Frossyniotis, D., Likas, A. \& Stafylopatis, A. (2004). A clustering method based on boosting, Pattern Recognition Letters, 25, Elsevier B.V., pp.641-654.

Wang, R., dkk. (2011). K-means Clustering Algorithm Application in University Libraries, Cognitive IEEE Informatics \& Cognitive Computing $\left(\right.$ ICCI* $\left.^{*} C \mathrm{C}\right)$, pp.419422.

Ahalya, G. \& Pandey, H.M. (2015). Data Clustering Approaches Survey and Analysis, IEEE Futuristic Trends on Computational Analysis and Knowledge Management ABLAZE, pp.532-537.

Elssied, N.O.F., Ibrahim, O. \& Osman, A.H. (2014). Enhancement of spam detection mechanism based on hybrid k-mean clustering and support vector machine, Journal of Soft Computing, vol.19, pp 32373248.

Li C.A. (2009). A new clustering algorithm using attribute boosting, IEEE International 
Conference on Management and Service Science (MASS '09).

Rashedi., E. \& Mirzaei., A. (2011). A Novel Multiclustering Method for Hierarchical Clusterings Based on Boosting, IEEE 19th Iranian Conference on Electrical Engineering.

Li., C \& Wu T. (2006). A Boosted Clustering Algorithm for Distributed Homogeneous Data Mining, IEEE The 6th World Congress on Intelligent Control and Automation.

Lisangan, E.A., Musdholifah, A. \& Hartati S. (2015). Two Level Clustering for Quality Improvement using Fuzzy Subtractive Clustering and Self-Organizing Map, TELKOMNIKA Indonesian Journal of Electrical Engineering, II(15), pp.373-380.

Prasetyo, E. (2012). Data Mining - Konsep dan Aplikasi Menggunakan MATLAB, ANDI, Yogyakarta.
Ashlock, D. dan Guo, L. (2007). Evolutionary Parameter Setting of Multi-clustering, IEEE Symposium on Computational Intelligence in Bioinformatics and Computational Biology (CIBCB).

Tan, Pang-Ning., Steinbach M. \& Kumar V. (2006). Introduction to Data Mining, Pearson Inc., New York. 